\title{
Los principios del proceso penal
}

\author{
ENRIQUE RUIZ VADILLO \\ Presidente de la Sala Penal del tribunal supremo y \\ del Instituto Europeo de España. Profesor de la Universidad
}

Es para mí un motivo de orgullo y satisfacción encontrarme en este preciosa y encantadora ciudad de Melilla en la que viví de muy pequeño, en la que nació mi hermano y de la que mis padres guardaron siempre un recuerdo gratísimo e imborrable.

Al Excmo. Sr. Alcalde de la ciudad, don Ignacio Velázquez Rivera, a la UNED y al Consejo General del Poder Judicial nuestra gratitud. También a la Dirección Provincial del Ministerio de Cultura.

Encontrarme en este entrañable ciudad y al lado de unos compañeros tan queridos para mí como el magistrado del TS don Luis Román Puerta Luis y el también magistrado y ahora Fiscal General del Estado don Carlos Granados Pérez, a los que me unen no sólo lazos indestructibles de compañerismo sino sobre todo afecto, admiración y agradecimiento, sentimientos que perdurarán en mí mientras viva, es especialmente grato, como lo es la presencia del Presidente del Tribunal Superior de Justicia don Manuel Rodríguez, con el que tuve la suerte de compartir estas tareas en Bilbao, la de don Manuel Torres, querido Presidente de Málaga y de 
mis entrañables compañeros don Ignacio Sierra y don Antonio Marín. Para José Cano compañero de promoción un abrazo muy fuerte.

IDEAS GENERALES

Probablemente los temas que están siendo objeto de consideración en este importante foro alcancen en la actualidad una trascendencia realmente esencial para nuestro futuro. En nuestra parcela como ha de organizarse el proceso penal para que sirva de verdad a su destino, en una Comunidad organizada bajo los principios que acompañan a todo Estado de Derecho Democrático y social como el nuestro.

Digamos ya de entrada que el fin no justifica los medios y que si el proceso responde de verdad a los principios a los que nos vamos a referir, jamás pueden temerse impunismos no queridos y que con evidencia tanto perjudican desde el punto de vista de la confianza que los ciudadanos han de tener en sus instituciones.

El Ordenamiento jurídico penal forma una unidad indestructible. Así, el Derecho penal sustantivo, el procesal y el penitenciario, (Jesccheck). Todo ha de conducir a una efectiva y profundamente humana realización de la Justicia penal.

En esta delicada aventura estamos embarcados Abogados, Fiscales y Jueces, cada uno desde la perspectiva que el Ordenamiento nos asigna. Mi confianza en la Abogacía es total. Los Abogados son piezas esenciales en la realización de la Justicia. Por ello mismo, las garantías que deben rodear su actividad son, en definitiva, garantías de la Justicia. Señor Decano, permítame que le exprese mi felicitación por dirigir una Corporación tan ilustre y noble y mi gratitud por la colaboración que presta a la UNED y a la Justicia de los tantos elogios que he oído a mi 
querido compañero Enrique Peralta, artífice con sus colaboradores de estas Jornadas.

Como ha dicho el Presidente del Tribunal Supremo y del Consejo General del Poder Judicial, don Pascual Sala Sánchez, a todos los poderes del Estado impone la Constitución un doble mandato: velar por la protección de los derechos fundamentales y evitar su transgresión. Los derechos fundamentales son derechos en permanente desarrollo y expansión. No hay un catálogo cerrado, dice, ni contornos fijos.

\section{EL DERECHO PENAL SLSTANTIVO}

Al Derecho penal hay que verlo como lo que realmente es: como la parte del Ordenamiento jurídico que defiende las bases estructurales de la convivencia en una paz construida sobre la Justicia. Ahí están todos los derechos fundamentales: derecho a la vida (con toda su amplia problemática: suicidio y eutanasia, transfusiones de sangre a quienes su Religión se lo prohíbe, huelgas de hambre en las prisiones, torturas y malos tratos), derecho a la libertad ideológica y religiosa, libertad y seguridad, honor, intimidad personal y familiar, imagen, secreto de las comunicaciones, elección libre de residencia, libre difusión del pensamiento, derechos de reunión y manifestación... Y todo ello se protege poniendo límites al Poder del Estado y a la tarea de los jueces. Como debe ser, hasta el punto de que el Código penal viene a ser, desde esta perspectiva, como el Derecho protector de quienes por unas u otras razones y en unas $\mathbf{u}$ otras circunstancias incurre en la delincuencia.

Por ello hay que aplaudir el Proyecto de Código penal de 1994 que, en este orden de cosas, presenta un diseño proyectado hacia esta defensa. Cuando el Jurado se haga efectivo el Pueblo podrá conocer las grandes dificultades que supone juzgar y aportar también su sensibilidad frente a una serie de problemas de especial significación.

Sin duda es tan difícil y compleja la tarea que, en mi modesta opinión, los jueces tenemos que hacer un esfuerzo sobrehumano para hacernos 
entender por nuestros ciudadanos, explicando por qué hacemos lo que hacemos y cómo lo hacemos, sobre la base de una permanente humildad.

Estimo que en esta gran tarea tenemos que estar junto a nuestros colegas europeos para construir o tratar de construir un mundo mejor donde impere la Justicia que todos queremos capaz de dar Paz auténtica a los Pueblos. Esa Europa en la que nos va a unir es, sobre todo, los ideales comunes de Libertad, de Igualdad, de Justicia, de Solidaridad, nunca frente a nadie y siempre para ayudar a cuantos lo necesiten.

\section{EL. PANORAMA ACTUAL}

Cuando se habla de los Principios del Proceso Penal, a los que enseguida haremos referencia, nos planteamos nada más y nada menos que el problema, muy serio y transcendente como ya hemos dicho, de cuál es su fin, cuáles sus límites y las vías utilizables para equilibrar las exigencias de una institución que ha de procurar la realización de la justicia que demanda legítimamente la sociedad y, al mismo tiempo, que lo haga con plena satisfacción y con un reconocimiento incondicionado, de los derechos fundamentales del acusado, lo que significa respeto a su intimidad, dignidad y libertad que sólo de manera excepcional y siempre por una decisión judicial motivada (art. $120 \mathrm{CE}$ ), salvo casos muy especiales, pueden lesionarse. Me refiero especialmente a las entradas y registros en domicilios, intervenciones telefónicas, ocupación de correspondencia y ordenadores personales, intervenciones corporales, seguimiento con cámaras de vídeo de las actividades de una persona, etc. Invasiones que no se pueden, desde luego, descartar pero que han de practicarse de forma prudente, bajo control judicial y sujetas siempre al principio de proporcionalidad, en función de la gravedad y significación del hecho delictivo presunto que se pretende descubrir.

En resumen, estamos en presencia de un acontecimiento, el del proceso penal y su inevitable reforma, realmente trascendental para nuestro futuro. Cuando se oyen voces muy autorizadas y prestigiosas como la del profesor Vassalli, Ex Ministro de Justicia de Italia, que analizan la situación actual y 
futura con preocupación, es el momento de reflexionar de manera interdisciplinar, para evitar que se produzcan, a los que la Humanidad está tan acostumbrada, movimientos pendulares y desplazamientos peligrosos.

A veces, cuando las cosas no van bien, (pensemos en las nuevas formas de criminalidad tales como el crimen organizado y la delincuencia terrorista, el narcotráfico, los grandes delitos económicos capaces de hacer tambalear a ciertas economías, la prostitución infantil y juvenil organizada, etc), caemos en la tentación de utilizar medios poco apropiados para una lucha eficaz sin darnos cuenta de que no es esa la solución, que está única y claramente en el perfeccionamiento de las instituciones que ya tenemos: una policía cada día mejor preparada y más técnica, unos fiscales y jueces capaces de hacer frente con su preparación a estas nuevas formas de criminalidad y un proceso cada vez más perfecto que haga compatible su perfección con el afianzamiento de los principios que informen las Declaraciones Universales y Europeas a este respecto. Después de más de 200 años de esta primera Declaración es preciso un reforzamiento de los principios que garantizan la efectiva presencia de los derechos fundamentales del Ciudadano frente al Estado en todas las partes del mundo y a ello se pretendió contribuir con la redacción de las llamadas "Reglas de Mallorca" que son un Catálogo de Mínimos, en este orden de cosas y que redactamos un grupo de juristas por encargo de Naciones Unidas para luego someterlas a los correspondientes organismos internacionales.

Volvemos otra vez a la exposición de unas ideas generales: hay que armonizar mejor los derechos humanos con las exigencias de una Justicia eficaz. Ello conduce a un replanteamiento de muchos principios tradicionales. La tarea de los jueces de instrucción que se dice son jueces-jueces, jueces policías y jueces-investigadores (Tulkens); y frente a ellos se pone la mirada, a veces, en el llamado Juez de la Libertad, (Italia y Alemania, por ejemplo).

La verdad es que el Derecho procesal penal, como dice el profesor Tiedemann, experimenta, desde hace tiempo, un intenso viento de reforma en muchos países del mundo. El acierto de ustedes al organizar estas Jornadas con carácter general dirigidas a todos los procesos no puede ser, pues, mayor. 
En este sentido, se habla de la exigencia de Ley formal en cuanto afecte al proceso penal proyectado a la defensa de estos derechos, a la dialéctica principio de legalidad-principio de oportunidad porque, en las sociedades modernas se dice es imposible perseguir todos los delitos, etc. Enseguida vamos a tratar algunos de estos temas, de algunas de cuyas soluciones doctrinales y legislativas discrepo. La sociedad, se señala, no puede con la delincuencia organizada. Tampoco es cierto.

De ahí a hablar de un exceso de derechos sólo media un muy pequeño paso. "El hipergarantismo, se dice, hoy en Italia tolera y favorece el crimen". El clima en este sentido puede ser peligroso. Desde la perspectiva de los muchos años de experiencia en el mundo de la Administración de Justicia y en otros puestos de la Administración me permitiría someter al mejor juicio de ustedes este otro titular: "El hipogarantismo conduce al terror, al Estado policial, al desprecio de los derechos humanos y en definitiva a la injusticia". Frente a cualquicr tipo de delincuencia, el Derecho que es el arma poderosa de la sociedad, tiene respuestas eficaces para todos los problemas. Ahí están los jueces como dijo al Enviado del Emperador, el Molinero de Postdam.

Es necesaria una cultura social que haga conocer a los ciudadanos, de verdad, lo que el Derecho supone y representa y que frente a una absolución, comprendan que ello significa, no sólo para los absueltos, sino también para el resto de los ciudadanos, lo mejor teniendo en cuenta que también así se realiza la justicia.

¿Por qué no podemos quedarnos en un Sistema de garantías, firmes, seguras, ciertas, inconmovibles; que supongan la plataforma inexcusable para que el Derecho penal pueda satisfacer las ansias de justicia que demanda nuestra sociedad? Una cosa son las concesiones gratuitas y estériles respecto de las pruebas desde una perspectiva puramente formal y otra, muy distinta, la defensa enérgica de los derechos, de todos los derechos y especialmente de los derechos fundamentales.

Cada día, si cabe hablar así, soy más entusiasta del auténtico Estado de Derecho Democrático. Y lo soy porque he vivido otras experiencias y. como todos los que nos dedicamos a estas actividades, he leído y estu- 
diado despacio la Historia del Derecho y de las Relaciones sociales y sabemos lo que supone bajar la guardia respecto de estos derechos.

¡Qué duda cabe que los jueces nos equivocamos, por eso hay que poner barreras legales para que estos errores, en la medida de lo posible, nunca prevalezcan!

La Declaración Universal de Derechos Humanos, el Convenio Europeo de Derechos Humanos, de Roma, con sus Protocolos Adicionales, el Pacto Internacional de Derechos Civiles y Políticos de Nueva York, la doctrina sabia y prudente del Tribunal Europeo de Derechos Humanos y del Tribunal Constitucional, han de constituir y seguir constituyendo la verdadera plataforma de nuestra actividad jurisdiccional y es sobre ella donde han de situarse las profundizaciones en la defensa de estos valores que hemos de seguir defendiendo a toda costa.

A veces se piensa, creo, respetuosamente, con equivocación. que las garantías conducen fatalmente al impunismo. Nada más lejos de la realidad. Al impunismo conducen los procesos penales mal tramitados y peor desarrollados, cada vez menos, por fortuna.

Una instrucción que tenga por esencial finalidad preparar el juicio oral, no sustituirle; una conciencia general de que es en este acto, (decisivamente importante), y no antes, en el que han de probarse los hechos delictivos y las correspondientes participaciones como autores, cómplices y encubridores, es definitivamente importante.

Naturalmente que ello no conlleva a declarar carente de valor todo lo que se hizo en la fase sumarial o de investigación, si en ella se actuó bien y con todas las garantías. En este sentido, la doctrina jurisprudencial del Tribunal Constitucional, (así, entre otras muchas la muy reciente de 9 de mayo de 1994). Como también tendrán validez aquellos informes que se unen al atestado y que tienen la significación de una prueba pericial si no se solicita su aclaración o corrección en el juicio oral.

Por ello, a mi juicio, la búsqueda del perfeccionamiento del sistema debiera consagrarse por vía legislativa, pero que ya puede realizarse una especie de prueba anticipada ante el juez de instrucción en presencia del Fiscal, de la Acusación, si está personada y obviamente de la Defensa dando fe 
el Secretario Judicial en la que se oiría al testigo que probablemente no podrá comparecer, por razones de enfermedad o de residencia: la mujer de nacionalidad extranjera que es objeto de una agresión sexual y que no puede permanecer en España en espera del juicio y a la que igualmente le resulta muy difícil realizar un viaje largo y costoso para comparecer en el acto del juicio oral. Si a ello se une, como en los supuestos de apelación, habría de hacerse obligatoriamente, la obtención de un vídeo con imagen y sonido que se acompañaría con la fehaciencia del Secretario judicial al Tribunal "a quo" o al de apelación respectivamente, creemos que sólo faltaría una mínima "inmediación", no nunca, ni contradicción ni plenitud de garantías.

Es también muy importante que las actas sean expresivas y legibles, así como una generalización del recurso de apelación, aunque se construya con unas ciertas limitaciones a la aportación de pruebas, como ocurre en la actualidad.

El tema de la imparcialidad del juez ha de situarse dentro de un marco de serenidad, sin encontrar parcialidades, aunque sean objetivas, allí donde no las hay. No toda intervención de un juez en un procedimiento puede acarrear su incompatibilidad para conocer cuestiones posteriores si no se han tomado decisiones que impliquen una especie de predeterminación (V: STC 9 de mayo de 1994).

Sí es fundamental la motivación de las sentencias. La motivación transforma actos puros de poder, en actos de razón y de razonabilidad. Pone el acento de la decisión judicial en la "autorictas" y no en la "potestas". El Tribunal Constitucional mantiene una postura absolutamente prudente y sensata sobre esta exigencia. Basta que la motivación sea suficiente, es decir proporcional a la complejidad del problema (V. STC 25 de abril de 1994), y no afecta a la exigencia constitucional si no es relevante para el fallo (STC 25 de octubre de 1993).

Por supuesto sí es esencial cuanto afecta a la asistencia letrada que es algo más que defensa. Ello supone libertad de comunicación e incluso a nuestro modesto entender debiera suponer que el Abogado haya de tener una mayor intervención en las declaraciones de los detenidos (V. STS de 7 de febrero de 1994). 
Finalmente, hay que construir un recurso de casación que sirva de verdad a la armonización en la aplicación del Derecho penal (aunque la idea es generalizable a todos los órdenes jurisdiccionales), en toda España. Me parece que en ese sentido (que es el que marcó nuestro Presidente del Tribunal Supremo en el último Discurso de Apertura de Tribunales), marchan las preocupaciones actuales.

A la hora de abordar un tema de política legislativa, dice el profesor Gimeno Sendra, como lo es el de la reforma procesal penal, conviene despejar como cuestión previa un presupuesto de partida cual es el de la función actual del proceso penal.

En este orden de cosas, como en tantos otros, la tarea de una prensa libre e independiente, de unos medios de comunicación especialmente sensibles a la realidad social, es fundamental.

Antes hablaba de una cultura del Pueblo que reciba con satisfacción. (la crítica siempre legítima y necesaria es otro problema) las absoluciones o las condenas a penas inferiores a las que en su alma pudiera desear, en el convencimiento de que, unas veces con acierto y otras veces sin él, (¿dónde está la verdad, qué es verdad?), los jueces y tribunales han de aplicar, en efecto, el Derecho penal cuando proceda, es decir cuando se prueba un hecho que reviste caracteres de delito o, en general, de infracción penal y, además, se acredita quién o quiénes intervinieron en él, sin olvidar que al individualizar la pena entran en juego todos los factores que han de coadyuvar a que las penas, todas, pero especialmente las privativas de libertad, estén orientadas, conforme establece nuestra Constitución, hacia la reeducación y reinserción social (art. 25.2).

Pero, además, debe decidir cuando proceda, la puesta en libertad del acusado y no ordenar la adopción de otras medidas de investigación que aquellas que sean necesarias y proporcionadas al fin perseguido, ni 
tampoco puede decidir medidas cautelares, embargos, etc, que no correspondan con arreglo a la ley interpretada restrictivamente y debe, por último, decidir todo aquello que sea conveniente en defensa y protección de la víctima, (el gran convidado de piedra del proceso penal, aunque, por fortuna, cada vez lo es menos) hasta llegar, cuando sea procedente, a la declaración de la correspondiente responsabilidad civil, directa o subsidiaria que, a nuestro entender, no debiera nunca separarse del proceso penal por razones de economía procesal que, en este caso, son de estricta justicia.

Sólo así se construirá un proceso justo que es un derecho que tienen todas las personas con una acentuación de los principios de celeridad y eficacia y un fortalecimiento de las garantías correspondientes.

En este sentido, hay que señalar con satisfacción todo lo que el nuevo Estado de Derecho Democrático y Social nacido de la Constitución de 1978 ha supuesto. Citemos, como muestra, la reforma del art. $1^{\circ}$ del Código Penal, auténticamente y en sentido altamente positivo, revolucionaria, que ha consagrado de verdad un derecho penal de culpabilidad y todas las reformas de la Ley de enjuiciamiento criminal que aun siendo una Ley verdaderamente modélica ha sido puesta al día con acierto en relación con la defensa de los Derechos Fundamentales.

Esta es la confianza que pueden y deben tener los ciudadanos frente a una Judicatura que lucha de corazón por hacer realidad estos ideales y con un Sistema que permite, en general, conseguirlo. Como ha dicho Franz Klein, el mejor derecho material de nada sirve si no cuenta para su aplicación con un buen proceso.

La Ley procesal penal regula un buen proceso, que las leyes posteriores en relación con este tema concreto han ido estropeando, desde la instauración de los llamados procedimientos de urgencia en los años cincuenta y sesenta, pasando por las últimas reformas que en nuestra opinión, al menos en muchos de sus aspectos no han sido acertadas. 
El proceso penal, desde la perspectiva de los principios que lo gobiernan, y sin ningún afán de exhaustividad, puede quedar enmarcado en este esquema:

Principio de legalidad. Principio de acceso a los tribunales. Principio de equilibrio y proporcionalidad. Principios de contradicción, inmediación, oralidad y publicidad. Principio acusatorio y principio de presunción de inocencia unido al de libre valoración de la prueba.

Todo el cuadro se puede reducir todavía más: búsqueda de la verdad real o histórica pero no a cualquier precio; defensa incondicionada de los derechos fundamentales del acusado; proscripción de toda indefensión y presunción de inocencia.

\section{PRINCIPIO DE LEGALIDAD}

La Constitución, en expresión afortunada del profesor Sánchez Agesta, es un Derecho fundamental de organización y en frase igualmente feliz del propio Tribunal Constitucional, es la Ley Fundamental y Fundamentadora del Ordenamiento Jurídico. No es un catálogo de principios, es la norma suprema que además como ha dicho el profesor Hernández Gil, maestro de todos y uno de nuestros más ilustres juristas, exige una legitimidad no sólo formal sino también material, relativa al contenido y a los fines de la norma, transformándose así, más que en un Sistema de Normas que lo es, en un Sistema de Valores.

El Ordenamiento jurídico forma, pues, un todo imparcelable en el que la Justicia, como horizonte de grandeza, de armonía y equilibrio, la certeza como seguridad jurídica y el bien común como proyección de todo cuanto él representa, enlaza con la realidad social del momento en que la norma jurídica ha de hacerse efectiva, de acuerdo con el art. 3.1 del Código Civil.

El principio de legalidad alcanza en este orden de cosas una muy profunda significación. Está reconocido expresamente de manera muy genérica por la Constitución, (art. 9.3) por el Código penal y por la 
LEGrim. También por la Ley General Penitenciaria. Como dice el profesor Almagro Nosete, en las sociedades actuales, los sistemas represivos tratan de conciliar la protección del orden social con la salvaguardia de las libertades individuales. Y esta función que inicialmente se refiere a las víctimas del delito y a la propia sociedad, en cuanto son sus libertades y la seguridad ciudadana lo que se protege con el sistema punitivo en general, sucesivamente se extiende al sujeto posible delincuente que obviamente goza también de los derechos a la libertad y a la seguridad. En este sentido, el principio de legalidad que excluye las indeterminaciones legales y elimina los conceptos genéricos, (el Derecho penal, acaso como ninguno exige, taxatividad y certeza) que se prestan a interpretaciones multívocas, representa una manifestación de seguridad jurídica del ciudadano frente al sistema punitivo.

Si nos damos cuenta, cuando se habla de garantías hacia al acusado, y se cae en la tentación de que estas pueden ser excesivas; acaso no se piensa con el suficiente detenimiento que la mayor víctima del proceso penal puede ser y lo será el propio acusado si es inocente. De ahí nace la convicción de que el Sistema de garantías en el enjuiciamiento criminal ha de ser absoluto y total. Otra cosa es, después, la reacción penal que frente a un acusado condenado haya de tomarse en función de la naturaleza del delito y de la peligrosidad social (penas y medidas de seguridad).

Ya hemos indicado que el principio de legalidad se proyecta también al proceso penal, cuyas normas son indisponibles, ofreciendo, como ya dijimos, un carácter de necesariedad que excluye la posibilidad de cualquier acuerdo o disposición privada para solucionar el conflicto originado por la producción del hecho delictivo, como, con acierto, señala Almagro Nosete.

La legalidad tiene una proyección extraordinariamente importante. La ley quiere que el enjuiciamiento criminal y la propia condena penal no signifiquen nunca la pérdida de dignidad de la persona que ha de sufrir la pena y que se respete su intimidad y hasta su libertad, en la medida en que sea compatible con el cumplimiento de la sanción.

De ahí las medidas que el Ordenamiento jurídico toma para prevenir todo cuanto jurídica y humanamente sea posible, el error judicial. De 
ahí también toda la teoría de la nulidad de la prueba que se practica fuera de los cauces de la legalidad y que afecta a las entradas y registros verificados sin cumplimentar las exigencias legales, a las interceptaciones telefónicas, cuando se llevan a cabo fuera de los cauces de la legalidad (decisión judicial, concreción, motivación, control, etc), o las intervenciones corporales en los supuestos en que no se cumplen los requisitos que hay que entender inexcusables antes de autorizar una invasión de la intimidad tan grave como la que estas intervenciones del cuerpo humano representan y significan. También debemos incluir en este apartado el principio "in dubio pro reo".

\section{DERECHO A UN PROCESO JUSTO}

Nuestra Constitución, absolutamente garantista, que sitúa a la persona humana en el centro mismo de sus preocupaciones más esenciales, incluye en varios de sus artículos y más en concreto en el 24 , una serie de derechos que incluso parecen repetitivos pero que, sin duda, pretenden no dejar fisuras por donde pudieran introducirse quiebras al Sistema. Tutela judicial efectiva. Proscripción de toda indefensión, Derecho al juez ordinario predeterminado por la ley, a la defensa y a la asistencia de letrado, a ser informada de la acusación formulada contra una persona, a un proceso público sin dilaciones indebidas y con todas las garantías, a utilizar los medios de prueba pertinentes para la defensa, a no declarar contra sí mismo, a no confesarse culpable y a la presunción de inocencia.

La verdad es que no puede pedirse más. La relación es algo que excede con mucho de un catálogo de derechos, es, en definitiva, la consagración constitucional de las garantías que corresponden al acusado, pues el precepto aunque con proyección general, tiene una preocupación muy directa e inmediata en relación con el llamado Derecho sancionador.

De ninguna manera representa esta extraordinaria y afortunada declaración, una barrera para el eficaz enjuiciamiento de los delincuentes, ni siquiera una dificultad, si se actúa como es debido. La naturaleza del derecho a la 
tutela judicial efectiva, ha dicho el Tribunal Constitucional en muchas sentencias, así entre otras, en la de 15 de noviembre de 1990, es la de un derecho de prestación que sólo puede ejercerse por los cauces que el legislador establece $o$, dicho de otro modo, es un derecho de configuración legal.

\section{EQUILIBRIO Y PROPORCIONALIDAD}

La justicia es un valor supremo junto con la libertad, la igualdad y el pluralismo político (art. 1.1 CE). Pero todos ellos tienen una cierta consideración de conceptos indeterminados. Es la ley, que representa la voluntad del Pueblo por medio de sus legítimos representantes, quien ha de fijar para cada caso y para cada situación, con sujeción estricta a la Constitución que es lo justo y lo injusto en cada momento. De ahí la movilidad y el dinamismo de la vida jurídica.

Ahora bien, existe una especie de prueba irrebatible, desde el punto de vista del conocimiento humano, para detectar la Justicia. Esta es la comprobación de si en la norma o en la decisión que corresponda impera el equilibrio y la proporcionalidad.

El principio constitucional de proporcionalidad, dice el profesor Gimeno Sendra en el prólogo a la obra del profesor Nicolás González Cuéllar Serrano constituye un instrumento utilísimo al servicio de la efectividad de los derechos fundamentales y, en definitiva, de la libertad, configurada en el art. 1.1 de la Constitución como "valor superior del Ordenamiento". De su vigencia se deducen fecundas consecuencias prácticas en relación con distintas medidas restrictivas como la interceptación de comunicaciones, la entrada y registro, la detención, la prisión provisional... La regulación y aplicación de toda injerencia estatal, en resumen, debe realizarse sin menoscabo del principio de proporcionalidad, lo cual exige del legislador: de los jueces y de la Administración el conocimiento del principio y su cumplimiento; puesto que, además, dado su rango constitucional, puede ser reclamado por los particulares, tanto ante la jurisdicción ordinaria como la constitucional, por la vía del recurso de amparo. 
Ahí está la grandeza del Derecho. Él es precisamente la búsqueda constante y rigurosa de la proporción que ha de ser la medida del acierto de cualquier norma o decisión. La motivación misma en cuanto a su configuración y extensión, la adopción de medidas cautelares, la determinación de las medidas que en el curso de una investigación hayan de tomarse... todo ha de ser proporcional.

Atendida la finalidad de esta modesta exposición ante un auditorio especialmente cualificado, que no es otra que la de compartir unas jornadas de expresión de inquietudes comunes, es obvio que no podemos hacer un estudio detenido de todos los principios que informan el proceso penal, que, además, han sido objeto de estudio o lo serán por los verdaderamente especialistas en cada uno de los temas y de cada uno de los órdenes jurisdiccionales, sino más sencillamente, dejar constancia de una serie de preocupaciones en orden a nuestro presente y a nuestro más inmediato futuro.

Antes decíamos, y ahora repetimos, que los principios que informan el proceso penal son como una serie de tupidas redes, unas superpuestas a las otras, con coherencia y armonía, que tratan de evitar el error en la administración de justicia y, en el caso que examinamos, en la justicia penal.

Todo está dispuesto para que en el escenario donde se va a desarrollar el proceso penal, se pueda probar todo lo que se pueda probar, a la luz de los ciudadanos y de los medios de comunicación, con inmediación, (que los jueces puedan captar bien lo que los inculpados, los testigos, las víctimas, dicen y lo que callan y los gestos, ;el lenguaje de los gestos al que se ha referido nuestro ilustre académico, el profesor Laín Entralgo!), con contradicción, (el cruce de preguntas y repreguntas de donde surge la verdad, la apreciación de lo que existe de contradictorio entre lo que se dijo en la fase de investigación y lo que se dice en el juicio oral). Es decir, en un acto en el que por ser oral nada queda sumergido bajo las escrituras que pudieran representar formas de ocultación y esoterismo 
con publicidad que sólo puede ceder, y a nuestro juicio, únicamente por vía selectiva, frente a los derechos de la víctima, a la que el Derecho penal ha de proyectar toda su inquietud, sensibilidad y preocupación.

\section{PRINCIPIO ACLSATORIO}

El principio acusatorio viene a ser como la quintaesencia de la proscripción de la indefensión. Nada hay más triste ni más lamentable que un ser indefenso. Por ello, frente a un acusado extranjero que no conoce nuestra lengua, frente a ciertos marginados sociales que, apenas si se dan cuenta por su propia marginalidad de lo que se les puede venir encima, ¡cuánta sobrecarga de defensión hay que poner!

El principio acusatorio es un magnífico instrumento técnico que tanto cuida el Tribunal Europeo de Derechos Humanos, el Tribunal Constitucional y la Sala Penal del Tribunal Supremo.

Sólo el que está informado de la acusación puede defenderse eficazmente. Frente al fantasma de una acusación imprecisa o indeterminada ¿quién puede actuar con probabilidades de éxito? El derecho a la tutela judicial efectiva comporta, dice la STC de 21 de abril de 1987, entre otros, el derecho a ser informado de la acusación como primer elemento del derecho de defensa que condiciona a todos los demás, no pudiendo sacrificarse en aras de una práctica material (STC de 3 de marzo 1989), siendo la verdadera acta de acusación, cuyo conocimiento es indispensable para una eficiente defensa, el escrito de calificación del Fiscal o de las acusaciones por lo que los motivos de la detención y del procesamiento son interinos y están subordinados a aquella calificación (STC 25 de marzo de 1987).

Por consiguiente:

1. Sin acusación no puede haber condena y si hubo acusación y se retiró tampoco es viable ésta. La razón es bien elemental y sencilla: el proceso penal es una especie de tríptico en el que los tres vértices han de estar ocupados y serlo por distintas personas: el acusador, el acusado 
y el juez. Si la posición del acusador la ocupa el juez, se rompe definitivamente el equilibrio del sistema.

2. La acusación ha de precisar el hecho nuclear sobre el que construye su calificación que no podrá variar el juzgador, así como habrá de determinar las personas responsables y el concepto bajo el cual ha de responder, fijando igualmente las circunstancias agravantes que, a su juicio, concurran, sin que el tribunal pueda incorporar ninguna otra aunque su existencia sea, en principio innegable como puede suceder con la reincidencia (STS 24 junio 1994).

3. Es absolutamente correcto que la Acusación modifique sus conclusiones provisionales y califique de distinta manera los hechos o las participaciones sin que ello implique indefensión, puesto que si la Defensa no se encuentra preparada para dar respuesta a la nueva calificación, utilizada la expresión en sentido amplio, lo que tiene que hacer es pedir la suspensión, (v. art. 793.7 LECrim).

4. Sin variar los hechos nucleares, sí los periféricos, el tribunal puede calificar de manera distinta a como lo hizo la acusación más grave, si el nuevo delito es homogéneo y lleva aparejada menos pena que el que fue objeto de acusación. Así se forman las columnas de modalidades delictivas que el tribunal puede recorrer pero sólo hacia abajo; por ejemplo asesinato, homicidio, lesiones del art. 421, lesiones del art. 420, lesiones falta. Robo con fuerza en las cosas, cualificado, simple y hurto-delito y hurto falta. Alevosía y abuso de superioridad, etc.

5. Como ya dijimos, el tribunal no puede apreciar circunstancias agravantes no recogidas en el escrito o escritos de calificación y. según el criterio jurisprudencial, sobre el que tengo algunas amplias aunque muy respetuosas reservas, la apreciación por las acusaciones de una eximente incompleta o de una circunstancia de atenuación, simple o cualificada, también vincula al tribunal sentenciador.

6. El principio acusatorio no cede ni siquiera cuando el juez o tribunal hacen uso de la facultad que les concede el art. 793.6 LECrim. o el 733 de la misma Ley respectivamente. Sólo si la acusación acepta la "invitación" que se la formula y asume la nueva calificación el juzgador podrá extender su condena al nuevo delito. 
7. De ahí la importancia excepcional que alcanza el Ministerio Fiscal, en la actualidad todavía mayor, si cabe, con el nuevo sistema, pues en sus manos está el calificar alternativamente los hechos de dos o más maneras cuando la lógica jurídica lo aconseje. Por ejemplo, en los supuestos en los que se encuentra en la casa de una persona todo o gran parte de lo sustraído días u horas antes y no da explicación mínimamente satisfactoria de la posesión. Si se califica de robo o hurto, el tribunal puede perfectamente no obtener esta inferencia de lo probado. En cambio, si se somete al juzgador la calificación de receptación con ánimo de lucro, en forma de alternativa aquél podrá decidir en conciencia (art. 741 LECrim.).

\section{DILACIONES INDEBIDAS}

La indefensión no sólo se puede producir por la denegación de justicia sino también por el retraso en resolver sobre las pretensiones de las partes.

El tiempo juega un papel definitivo en el campo del Derecho, acaso, más todavía, en el jurídico-penal. Las condenas extemporáneas son contraproducentes y hacen un daño grave e innecesario. La víctima, (recuerdo a los profesores Beristain, García Pablos, Landrove, al magistrado Martínez Arrieta, etc) cuando es indemnizada, si lo es, acaso llegue demasiado tarde. La sociedad misma contempla perpleja el ingreso en prisión de personas que delinquieron hace muchos años y que al parecer están ya reinsertadas en la sociedad...

En este sentido es fundamental evitar todas las dilaciones y por fortuna se va en ese camino y cuando por unas $u$ otras razones esto no puede conseguirse, debe ser el propio juez o tribunal quien utilice el Ordenamiento jurídico, en cuanto conjunto coherente y armónico para salvar la deficiencia, cuando ello sea posible. A nuestro juicio, el Código penal debiera contener una institución paralela a la prescripción: la cuasi prescripción y además utilizar a fin de conseguir las correspondientes sumas los tiempos libres y en vez de utilizar la interrupción hacer uso de la suspensión de los términos. 
Mientras tanto creemos y lo decimos con todo respeto para quienes no piensan así, acaso hubiera sido procedente utilizar la circunstancia atenuante por analogía, (núm. 10 del art. 9 del Código penal con referencia a la analogía iuris, art. 1.1 de la $\mathrm{CE}$ y no a la analogía legis). Me remito al estudio que en este orden de cosas realizó mi compañero don Carlos Granados y que me sirvió de base para otro mío que se publicó recientemente en el Boletín de Información del Ministerio de Justicia.

La conjunción de estas dos importantes instituciones es una conquista innegable y muy positiva de la doctrina del Tribunal Constitucional. En efecto, es imprescindible que una prueba de signo acusatorio, inequívocamente de cargo, se desarrolle ante el tribunal sentenciador en los términos ya examinados, con legitimidad de origen y de contenido, (excluyendo toda la prueba nula), bajo los principios de inmediación y de contradicción y oralidad... Pero, una vez que la prueba se ha practicado, es al juzgador de instancia a quien incumbe su valoración. No se puede, sobre los papeles, decidir qué testimonio era más creíble, ni dónde estaba la verdad, si en la declaración sumarial, es decir en la fase de investigación, o en el juicio oral. Las observaciones que el Tribunal Supremo hace en sus resoluciones, en este orden de cosas, no pretenden sustituir el criterio del tribunal "a quo" por el suyo propio sino, más sencillamente, apuntar fórmulas de armonización. Por ejemplo, cuando advierte de los peligros de la declaración de un coimputado contraria a su compañero: en la que puede existir animadversión, odio, deseo de venganza, deseo de resultar favorecido con su declaración inculpatoria, ofrecimientos o promesas, etc. Y ello es predicable también de los testigos y de las propias víctimas reales $o$ aparentes de un delito.

En cambio, me parece peligrosísimo y lleno de obstáculos introducir en la casación una fórmula de impugnación sobre la base de apreciar la suficiencia o insuficiencia de la prueba. Si hay prueba de cargo, el Tri- 
bunal Supremo no tiene nada que hacer en este sentido, si falta, hay que absolver, sin duda de ningún género.

Este es el equilibrio que la doctrina del Tribunal Constitucional ha conseguido entre la presunción de inocencia del art. 24.2 de la Ley Fundamental y el contenido del art. 741 de la Ley de Enjuiciamiento Criminal que así entendido es en todo conforme a la Constitución. En este orden de cosas me remito a las valiosísimas aportaciones del profesor Vázquez Sotelo.

No hay que tener miedo ni preocupación alguna frente a las fórmulas auténticamente garantistas porque ellas son el fundamento mismo del Estado de Derecho en el que queremos vivir y convivir, vivir unos con otros con mutuo y recíproco respeto, bajo un conjunto de leyes que conducen, precisamente por ser justas, a la Paz.

No cabe la menor duda de que si todo absolutamente dependiera del juicio oral las absoluciones crecerían improcedentemente, a veces por las amenazas que víctimas y testigos pueden recibir, a veces, también. por la piedad de quienes sufrieron el delito o lo presenciaron. Si en esa fase preliminar, que prepara, no sustituye al juicio oral, se actúa bien, como ya dijimos, y en trdo caso con presencia de Letrado, (que garantiza la legitimidad del acto) este caudal de actividad puede ingresar en el acervo probatorio con plenitud de garantías.

Es evidente que no sólo la prueba directa sino también la indirecta, circunstancial o por indicios, (muchas veces más segura que la primera) es apta para viabilizar una condena si en este segundo supuesto, se prueban los indicios, que han de ser plurales, y se fija con rigor el enlace de los indicios respecto de la conclusión condenatoria.

Agilizar la justicia es otra de las metas a conseguir cuanto antes, (y es mucho lo ya obtenido gracias al esfuerzo de nuestros jueces y tribunales) pero hay que hacerlo por caminos de ortodoxia lo que en mi modestísima opinión, y nunca más modesta que ahora, no se da cuando se instaura el 
principio de oportunidad en la persecución que a pesar de los esfuerzos que hago no entiendo y menos aún lo que se viene a llamar oportunidad reglada. En definitiva, si es la ley la que permite la suspensión incluso del fallo, habrá legalidad, en otro caso estaremos en los antípodas de la legalidad.

De esta manera, acelerando los procesos penales se evita la constante búsqueda, que me parece legítima y humanamente comprensible, de un recurso tras otro recurso con un fin exclusivamente dilatorio y, hasta a veces, con el designio por parte del acusado de burlar al final la acción de la justicia.

Si todos estos principios a los que nos hemos referido se complementan con un buen sistema penitenciario podremos sentir la satisfacción de encontrarnos, como me parece que por fortuna estamos, en un camino seguro y cierto de perfeccionamiento de nuestras Instituciones jurídico-penales.

Hace ya muchos años, en mi tesis doctoral dije, y ahora recuerdo con sosiego y paz en el espíritu, que el derecho penal no está reñido jamás, al contrario. y nada importa lo que los demás puedan pensar a este respecto, con la humanidad, con la sensibilidad y con el deseo, por encima de todo, de conseguir que esa mujer u hombre que está frente a nosotros, irrepetido e irrepetible, al que juzgamos, con la preocupación de si seremos capaces de acertar en esa tarea tan difícil y complicada, pueda cuanto antes reinsertarse en la sociedad y que ésta perdone y olvide, aunque cueste hacerlo muchas veces, y sepa incorporar a quienes, no se sabe por qué, delinquieron.

Muchas gracias. 